\title{
Chromium removal and water recycling from electroplating wastewater through direct osmosis: Modeling and optimization by response surface methodology
}

\author{
Zohreh Naghdali $^{1,2}{ }^{\circledR}$, Soleyman Sahebi ${ }^{{ }^{\circledR}}$, Reza Ghanbari ${ }^{4,2}{ }^{\circledR}$, Milad Mousazadeh $^{1,2}{ }^{\mathbb{D}}$, Hamzeh Ali Jamali $^{4,2^{*}}$ \\ ${ }^{1}$ Student Research Committee, Qazvin University of Medical Sciences, Qazvin, Iran \\ ${ }^{2}$ Department of Environmental Health Engineering, School of Health, Qazvin University of Medical Sciences, Qazvin, Iran \\ ${ }^{3}$ Research and Technology Center of Membrane Processes (RTCMP), School of Chemical, Petroleum and Gas Engineering, Iran \\ University of Science and Technology (IUST), Tehran, Iran \\ ${ }^{4}$ Social Determinants on Health Promotion Research Center, Qazvin University of Medical Sciences, Qazvin, Iran
}

\begin{abstract}
Background: Considering the carcinogenic effects of heavy metals, such as chromium, it is essential to remove these elements from water and wastewater. Direct osmosis is a new membrane technology, which can be a proper alternative to conventional chromium removal processes.

Methods: The wastewater samples were collected from an electroplating unit, located in Alborz industrial city, Qazvin, Iran. Magnesium chloride was used as the draw solution, and a semipermeable membrane (Aquaporin) was used in this study. The experiments were designed, using response surface methodology (RSM) and central composite design (CCD) with draw solution concentration (0.5$1.5 \mathrm{M})$, feed solution concentration $(4-12 \mathrm{mg} / \mathrm{L})$, and experiment time (30-90 minutes) as variable factors. The chromium concentration and water flux were also measured, based on atomic absorption spectrophotometry and water flux equation, respectively.

Results: Direct osmosis was highly efficient in chromium removal and water recycling. Water flux and chromium removal efficiency were $15.6 \mathrm{LMH}$ and $85.58 \%$, respectively, under optimal conditions (draw solution $=1.27 \mathrm{~mol} / \mathrm{L}$, feed solution $=4 \mathrm{mg} / \mathrm{L}$, and experiment time $=90 \mathrm{~min}$ ). In terms of validity, the results predicted by the quadratic polynomial model were in good agreement with the responses reported in the laboratory.

Conclusion: In direct osmosis, the use of magnesium chloride as the draw solution resulted in the acceptable chromium removal from electroplating wastewater. Using this method, chromium concentration in wastewater reduced to a level lower than the discharge standards, established by Iran's Department of Environment.

Keywords: Direct osmosis, Chromium removal, Electroplating, Optimization

Citation: Naghdali Z, Sahebi S, Ghanbari R, Mousazadeh M, Jamali HA. Chromium removal and water recycling from electroplating wastewater through direct osmosis: Modeling and optimization by response surface methodology. Environmental Health Engineering and Management Journal 2019; 6(2): 113-120. doi: 10.15171/EHEM.2019.13.
\end{abstract}

Article History: Received: 23 January 2019 Accepted: 27 April 2019 ePublished: 19 May 2019

\section{Introduction}

In many countries, especially developing countries, significant amounts of heavy metals enter the environment through industrial activities either directly or indirectly $(1,2)$. The most common heavy metals in industrial wastewater include arsenic, chromium, lead, cadmium, copper, nickel, and zinc, which are hazardous to human and environmental health (3-5). In terms of frequency, chromium is the seventh most abundant chemical element on the planet. Chromium is mostly found in the environment in two valence states, trivalent chromium
(Cr III) and hexavalent chromium (Cr VI); the latter state is hazardous to both human and environment $(6,7)$. Generally, the most important sources of chromium are leather, plating, tannery, and textile industries (8). In Iran, the standard chromium discharge from industrial wastewater into the environment is set at $0.5-1 \mathrm{mg} / \mathrm{L}$ (9). Therefore, chromium removal from wastewater seems essential. Currently, many physical, chemical, and biological processes, including chemical sequestration, air flotation, ion exchange, surface absorption, and membrane processes, have been proposed to remove heavy metals 
from industrial wastewater (10-13). Membrane filtration processes have various advantages, including low energy requirements, high separation efficiency, simple equipment requirements, and simple recycling of heavy metals (14). Today, membrane technologies, especially reverse osmosis, are the most extensively applied methods for water and wastewater treatment. However, in comparison with other membrane technologies, reverse osmosis requires more energy and costs, and results in severe membrane fouling (15). Recently, major attention has been paid to direct osmosis due to its various advantages, such as low energy requirements, low membrane fouling, simple reduction of membrane fouling, and increased water recycling. This technology, which is based on a natural phenomenon, is the process of spontaneous water diffusion across a semipermeable membrane. The driving force for the osmotic transfer of water from the feed solution into the draw solution is the osmotic pressure gradient between the solutions, without any need for external forces (16). In the conventional onefactor-at-a-time approach, only one factor or variable is examined at a time while keeping others fixed. This method is particularly valuable when the number of effective factors in the process is high, the duration of experiments is long, or costs are high (17). On the other hand, this method is unable to evaluate the interactive effects of factors and has a high error rate. Therefore, researchers employ the response surface methodology (RSM), which is a set of mathematical and statistical techniques $(18,19)$ for designing experiments, modeling, optimization, and analyzing the interactive effects of different parameters. In addition, central composite design (CCD) is one of the most commonly used arrangements of RSM in the design of experiments $(20,21)$. With this background in mind, the aim of this study was to optimize chromium removal and water recycling from electroplating wastewater, using direct osmosis process.

\section{Materials and Methods}

Pilot-scale study of direct osmosis

Figure 1 presents a general image of the pilot-scale process of direct osmosis in this study. This pilot study is a continuous system and consisted of a Plexiglas unit with two channels for the entry and exit of draw and feed solutions, an Aquaporin membrane (Aquaporin Asia Pte. Ltd, Singapore) with an effective area of $8 \mathrm{~cm}^{2}(4 \mathrm{~cm} \times 2$ $\mathrm{cm}$ ), and a two-way peristaltic pump (D500 model, Iran) for the transfer of solutions on the membrane sides. Due to the presence of proteins in the Aquaporin membrane structure, they have much more permeability than other membranes (22). The flow rate was set at $200 \mathrm{~mL} / \mathrm{min}$. Two Erlenmeyer flasks $(100 \mathrm{~mL})$ were used for the storage of draw and feed solutions. To measure the amount of permeate water through the membrane to the draw solution tank, a digital scale (0.01 g precision; Kern PCB 1000-2, Germany) was used.

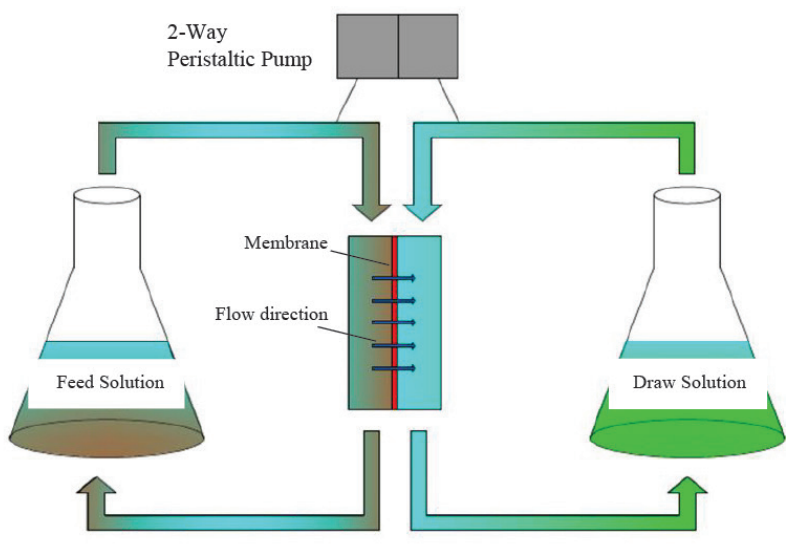

Figure 1. The pilot scheme of direct osmosis process.

Materials

Actual wastewater samples were collected from an electroplating unit, located in Alborz Industrial City, Qazvin, Iran. The baseline characteristics of the samples were as follows: chromium concentration, $14.51 \mathrm{mg} / \mathrm{L} ; \mathrm{pH}$ <2; turbidity, $21 \mathrm{NTU}$; and electrical conductivity, 4000 $\mathrm{ms} / \mathrm{cm}$. To prevent membrane fouling, the samples were passed through filters before use. The draw solution was prepared using magnesium chloride $\left(\mathrm{MgCl}_{2} ; \mathrm{Merck}\right)$. After each experiment, samples of draw solutions were analyzed to measure the amount of chromium passing through the membrane. The chromium concentration was measured using an atomic absorption spectrophotometer (BRAIC WFX-130).

\section{Experimental design}

The experiments were designed in Design Expert 7, based on CCD. Each independent variable (factor) was defined at five levels. The design points included factorial, axial, and central points. The independent variables were transformed into non-dimensional coded variables using Eq. (1):

$x_{i}=\frac{X_{i}-X_{0}}{\Delta X} \quad i=1.2 .3 \ldots . k$.

Where $x_{i}$ represents the non-dimensional coded value of the variable, $X_{0}$ indicates the value of $x_{i}$ in the axial point, and $\Delta X$ is the difference in values.

Experimental factors and their levels are presented in Table 1. To prepare the solution in these ranges, samples were diluted with tap water and their $\mathrm{pH}$ was adjusted in primary values. The $\alpha$ value was also measured $(\alpha=1.68)$ according to Eq. (2):

$\mathrm{A}=2^{\mathrm{n} / 4}=2^{3 / 4}=1.68(2)$

where $n$ represents the number of independent variables. Water flux $\left(\mathrm{L} / \mathrm{m}^{2} \mathrm{~h}\right.$ or $\left.\mathrm{LMH}\right)$ and chromium removal efficiency (\%) were considered as the dependent variables (responses). With regard to the studied factors, a total of 
20 experiments were designed, including eight factorial points, six axial points, and six central points, according to Eq. (3):

$N=2^{K}+2 K+C_{p}$

where $N$ represents the number of experiments, $K$ indicates the number of factors, and $C_{p}$ denotes the number of repeated points. The behavior of the system was studied using Eq. (4), which is a quadratic polynomial equation. All experiments were performed at laboratory temperature.

$$
\begin{aligned}
& Y=\beta 0+\sum_{i=1}^{k} \beta_{i} x_{i}+\sum_{i=1}^{k} \beta_{i i} x_{i}^{2}+ \\
& \sum_{i i \leq i}^{k} \sum_{j}^{k} \beta_{i j} x_{i} x_{j}+\ldots+e
\end{aligned}
$$

where $i$ is a linear constant, $j$ is a quadratic constant, $\beta$ is a regression constant, $k$ indicates the number of investigated and optimized factors in the experiment, and $e$ represents random error. After performing the experiments, data were analyzed using ANOVA and regression analysis. The models were modified by the omission of terms which were not significant at a confidence level of $95 \%$. In order to optimize chromium removal and water recycling, in the optimization section of the program (numerical mode), the level of factors was selected to be "in range", and responses were set at "maximized".

Analysis of water flux and chromium removal

Equation (5) was used to determine the amount of water flux during direct osmosis:

$$
J_{w}=\frac{\Delta m}{\rho A_{m} \Delta_{t}}
$$

where $J_{w}$ denotes the amount of water flux (LMH), $\Delta m$ represents the weight of permeate water passing from the membrane to the draw solution $(\mathrm{kg}), \rho$ indicates the specific mass of water $(1 \mathrm{~kg} / \mathrm{L}), A_{m}$ is the effective membrane surface area $\left(\mathrm{m}^{2}\right)$, and $\Delta t$ is the experiment time (hours).

In addition, chromium removal efficiency was calculated using Eq. (6):

$$
R(\%)=\left(1-\frac{C_{P}}{C_{f}}\right)
$$

where $R$ indicates chromium removal by the membrane
(\%), $C_{P}$ is chromium concentration in the draw solution $(\mathrm{mg} / \mathrm{L})$, and $C_{f}$ is chromium concentration in the feed solution $(\mathrm{mg} / \mathrm{L})$.

\section{Results}

Table 2 presents the experimental design with actual and predicted results. Based on the results, the highest removal rate of chromium and water flux were $100 \%$ and $17.4 \mathrm{LMH}$, respectively.

Table 3 presents the results of ANOVA test regarding chromium removal from wastewater and permeate water flux through the membrane. $P$ value, probability of lack of fit (PLOF), R-squared $\left(\mathrm{R}^{2}\right)$, adjusted $\mathrm{R}^{2}$, adequate precision (AP), standard deviation (SD), coefficient of variance $(\mathrm{CV})$, and predicted residual error sum of squares (PRESS) are also presented in this table.

Figures $2 \mathrm{a}$ and $\mathrm{c}$ present the normal probability plot of residuals and Figures $2 \mathrm{~b}$ and $\mathrm{d}$ presents the plot of internally studentized residuals versus the run number in chromium removal and water flux by direct osmosis. According to Figures $2 \mathrm{a}-\mathrm{c}$, the residuals had a normal distribution because the points were almost located on a straight line. Also, in Figures $2 b-c$, the residuals were independent of each other and did not follow a particular pattern, therefore, the assumption of data independence was confirmed.

Figure 3 demonstrates the contour plots for the interactive effects of independent variables in chromium removal from wastewater and permeate water flux through the membrane (by keeping other independent variables in the mid-range).

\section{Discussion}

Membrane processes have the potential to remove heavy metals from wastewater due to the inhibition of molecule and ion passage through the membrane. In this regard, ultrafiltration, nanofiltration, reverse osmosis, and electrodialysis methods have been applied to remove heavy metals (23). Direct osmosis, as a new membrane technology, allows water to pass through the semipermeable membrane due to the osmotic pressure difference. Unlike the reverse osmosis method, there is no need for extra energy in this technology (24).

The results of ANOVA test revealed that the quadratic model was a good fit to the experimental data. The

\begin{tabular}{|c|c|c|c|c|c|}
\hline \multirow{2}{*}{ Variables } & \multicolumn{5}{|c|}{ Coded values } \\
\hline & $-\alpha$ & -1 & 0 & +1 & $+\alpha$ \\
\hline Draw solution concentration (mol/L) & 0.16 & 0.5 & 1 & 1.5 & 1.84 \\
\hline Feed solution concentration (mg/L) & 1.27 & 4 & 8 & 12 & 14.73 \\
\hline Experiment time (min) & 9.55 & 30 & 60 & 90 & 110.45 \\
\hline
\end{tabular}
quadratic equations presented in Table 3 regarding chromium removal and water flux, show the significant

Table 1. The actual and coded values of independent variables 
Table 2. The central composite design (CCD) matrix with predicted and experimental results

\begin{tabular}{|c|c|c|c|c|c|c|c|c|}
\hline \multirow{2}{*}{$\begin{array}{l}\text { No. of experiment } \\
\text { (random) }\end{array}$} & \multirow{2}{*}{$\begin{array}{c}\text { No. of } \\
\text { experiment }\end{array}$} & \multirow{2}{*}{$\begin{array}{l}\text { Feed solution } \\
\qquad(\mathrm{mg} / \mathrm{L})\end{array}$} & \multirow{2}{*}{$\begin{array}{l}\text { Draw solution } \\
\text { (mol/L) }\end{array}$} & \multirow{2}{*}{$\begin{array}{l}\text { Experiment } \\
\text { time }\end{array}$} & \multicolumn{2}{|c|}{ Water flux (LMH) } & \multicolumn{2}{|c|}{$\begin{array}{c}\text { Chromium removal } \\
\text { efficiency (\%) }\end{array}$} \\
\hline & & & & & Predicted & Actual & Predicted & Actual \\
\hline 16 & 1 & 8 & 1 & 60 & 8.80 & 8.77 & 95.59 & 98.5 \\
\hline 9 & 2 & 1.27 & 1 & 60 & 14.14 & 13.9 & 77.02 & 77.08 \\
\hline 20 & 3 & 8 & 1 & 60 & 8.80 & 8.99 & 95.59 & 92.42 \\
\hline 4 & 4 & 12 & 1.5 & 30 & 9.10 & 9.5 & 78.50 & 80.56 \\
\hline 3 & 5 & 4 & 1.5 & 30 & 10.50 & 11.1 & 53.30 & 47.94 \\
\hline 5 & 6 & 4 & 0.5 & 90 & 9.17 & 9.5 & 99.86 & 98.81 \\
\hline 18 & 7 & 8 & 1 & 60 & 8.80 & 8.54 & 95.59 & 96.02 \\
\hline 1 & 8 & 4 & 0.5 & 30 & 5.02 & 5.2 & 88.88 & 93.57 \\
\hline 7 & 9 & 4 & 1.5 & 90 & 17.51 & 17.4 & 78.32 & 80.75 \\
\hline 14 & 10 & 8 & 1 & 110.45 & 9.49 & 9.3 & 92.66 & 90.73 \\
\hline 13 & 11 & 8 & 1 & 9.55 & 5.55 & 4.7 & 76.25 & 76.75 \\
\hline 11 & 12 & 8 & 0.16 & 60 & 5.13 & 4.6 & 104.62 & 100 \\
\hline 10 & 13 & 14.73 & 1 & 60 & 11.00 & 10.2 & 92.98 & 91.49 \\
\hline 8 & 14 & 12 & 1.5 & 90 & 9.64 & 10.2 & 87.04 & 83.36 \\
\hline 15 & 15 & 8 & 1 & 60 & 8.80 & 8 & 95.59 & 97.44 \\
\hline 6 & 16 & 12 & 0.5 & 90 & 6.82 & 6.95 & 93.63 & 100 \\
\hline 17 & 17 & 8 & 1 & 60 & 8.80 & 8.88 & 95.59 & 92.08 \\
\hline 2 & 18 & 12 & 0.5 & 30 & 9.15 & 10 & 99.13 & 97.71 \\
\hline 12 & 19 & 8 & 1.84 & 60 & 12.11 & 11.6 & 69.16 & 72.36 \\
\hline 19 & 20 & 8 & 1 & 60 & 8.80 & 9.8 & 95.59 & 97.34 \\
\hline
\end{tabular}

Table 3. The ANOVA results of quadratic models for water flux and chromium removal

\begin{tabular}{|c|c|c|c|c|c|c|c|c|c|}
\hline Responses & Final Equation as Coded Factors & $P$ value & PLOF & $\mathbf{R}^{2}$ & Adj. $R^{2}$ & AP & SD & CV & PRESS \\
\hline Water flux (LMH) & $\begin{array}{l}Y_{1}=8.80-0.94 A+2.07 B+1.17 C-1.38 A B-1.62 A C+ \\
0.72 B C+1.33 A^{2}-0.45 C^{2}\end{array}$ & 0.0001 & 0.21 & 0.97 & 0.94 & 23.91 & 0.74 & 7.9 & 31.17 \\
\hline $\begin{array}{l}\text { Chromium removal } \\
\text { efficiency (\%) }\end{array}$ & $\begin{array}{l}Y_{2}=95.59+4.74 A-10.54 B+4.88 C+3.74 A B- \\
4.12 A C+3.51 B C-3.75 A^{2}-3.08 B^{2}-3.94 C^{2}\end{array}$ & 0.0001 & 0.07 & 0.94 & 0.88 & 16.50 & 4.4 & 4.98 & 1382.05 \\
\hline
\end{tabular}

$P$ value: probability of error; PLOF: probability of lack of fit; AP: adequate precision; SD: standard deviation; CV: coefficient of variance; and PRESS: predicted residuals error sum of squares.

effects of feed solution concentration (A), initial concentration of draw solution (B), and experiment time (C). In addition, the interactive effects of these factors $(\mathrm{AB}, \mathrm{AC}$, and $\mathrm{BC})$, as well as their quadratic effects $\left(\mathrm{A}^{2}\right.$, $\mathrm{B}^{2}$, and $\mathrm{C}^{2}$ for chromium removal and $\mathrm{A}^{2}$ and $\mathrm{C}^{2}$ for water recycling), were significant. The coefficient of determination $\left(\mathrm{R}^{2}\right)$ is defined as the ratio of the explained variance to the total variance. The closer $R^{2}$ is to one, the higher is the model's accuracy in predicting responses (25). In this study, $\mathrm{R}^{2}$ values were 0.94 and 0.97 , respectively for chromium removal and water flux. In addition, the adjusted $\mathrm{R}^{2}$ coefficients (adj. $\mathrm{R}^{2}$ ), which are always lower than $\mathrm{R}^{2}$ (26), were 0.88 and 0.94 for chromium removal and water flux, respectively, which indicates the good fit of the models. Lack of fit was 0.2 and 0.07 for water flux and $\mathrm{Cr}$ removal, respectively. According to the report of Khoshnamvand et al, lack of fit value is calculated using the difference between sum of the squares for the experimental response variable and its predicted values by the model (19). In the case of significant lack of fit, the model is considered valid (18). AP is the signal-to-noise ratio, which compares the range of predicted values at the design points to the average prediction error. AP greater than 4 is generally considered favorable $(27,28)$. In this study, AP for chromium removal and water recycling was 16.50 and 23.91, respectively, which indicates the presence of good signals. In addition, the coefficient of variation (CV), which determines the repeatability of the model, is defined as the ratio of the estimated standard error to the mean response; the value of CV should not exceed $10 \%$ (29). In this study, CV values for water recycling and chromium removal were $7.9 \%$ and $4.98 \%$, respectively, which indicates that the models are repeatable. Similarly, the goodness of fit test was not significant for the responses $(P \geq 0.05)$, which also indicates the good fit of the models. As shown in Figure $3 \mathrm{a}$, by reducing the concentration of feed solution and increasing the experiment time, the water flux increased. The maximum water flux (18 LMH) was reported when chromium concentration was approximately $1.3 \mathrm{mg} / \mathrm{L}$, and experiment time was 


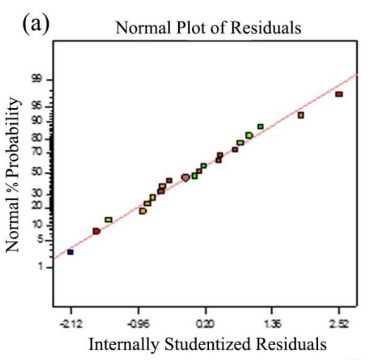

(b)

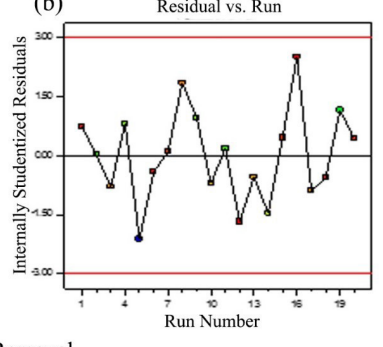

Cr Removal

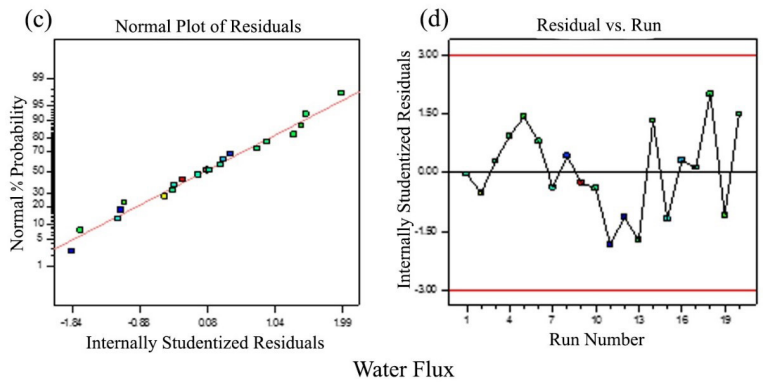

Figure 2. The normal probability plot of residuals (a and c) and internally studentized residuals versus the run number ( $b$ and $d$ ) for water flux and chromium removal.

about 110 minutes. The interactive effect of experiment time and feed solution concentration on the removal efficiency of chromium is shown in Figure 3b. According to this figure, with an increase in the concentration of feed solution and experiment time, the removal efficiency of chromium increased. Maximum chromium removal from wastewater was observed at a feed solution concentration of $9.5 \mathrm{mg} / \mathrm{L}$ and experiment time of 73 minutes; chromium removal efficiency was reported to be above 95\%. On the other hand, chromium removal efficiency decreased by increasing the concentration of feed solution and experiment time. It seems that the passage of chromium through the membrane pores reduces with time due to membrane fouling; consequently, chromium removal increases. However, water flux decreases over time due to membrane fouling and reduction of membrane pores. Water flux was not significantly affected by simultaneous changes in the concentration of draw solution and experiment time (Figure 3c). As shown in this figure, water flux increased due to increased osmotic pressure when higher concentrations of draw solution were used. However, water flux gradually decreased over time due to decreased osmotic pressure as a result of the dilution of draw solution. In this regard, Zhao et al (30) reported that by increasing the experiment time to five hours, water flux followed a decreasing trend when a cellulose triacetate membrane was used for nickel removal. However, by using a thin-film composite membrane, water flux was slightly increased over time. The time-dependent reduction of water flux may be due to the increased concentration polarization or membrane fouling due to the addition of nickel to the feed solution. As shown in Figure 3d, 100\% of chromium was eliminated within
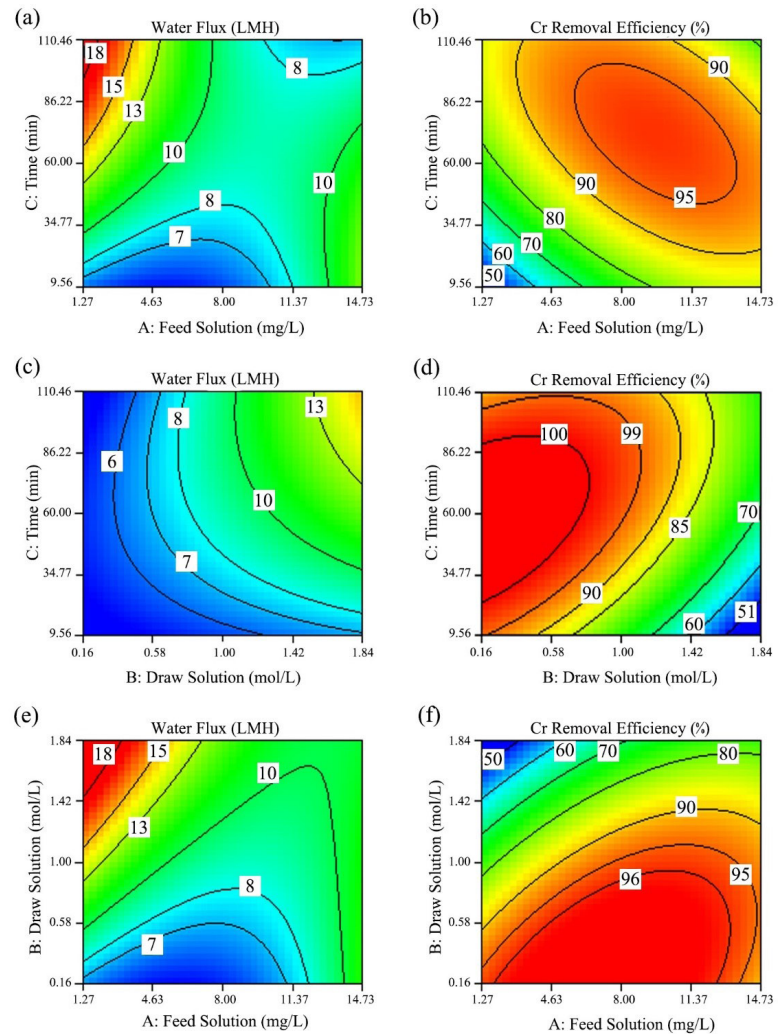

Figure 3. Response plots of the interactive effects of independent variables on the chromium removal and water flux.

20 to 86 minutes at $\mathrm{MgCl}_{2}$ concentrations below 0.8 $\mathrm{mol} / \mathrm{L}$. At higher concentrations, the removal efficiency of chromium decreased by increasing the concentration of draw solution and experiment time. The interactive effects of draw and feed solution concentrations on water flux and chromium removal are presented in Figures 3e and $f$. At low concentrations of feed solution, the water flux increased by increasing the concentration of draw solution. In fact, water flux reached the maximum level (18 LMH) at concentrations between 1.45 and $1.84 \mathrm{~mol} / \mathrm{L}$ (Figure 3e). Generally, an increase in the osmotic pressure difference between the feed and draw solutions increases the water flux. The results of studies by Vital et al (23) and Liu et al (31) showed that increasing the concentration of $\mathrm{NaCl}$ to $1.5 \mathrm{~mol} / \mathrm{L}$ as the draw solution, increased the water flux from 5 to $20 \mathrm{LMH}$. However, due to internal concentration polarization in the membrane, the increase in the concentration of draw solution does not always increase the water flux. On the other hand, with reducing the draw solution concentration, the driving force through the membrane was reduced, resulting in the reduction of water flux $(10,31)$. However, according to Figure 3f, at draw solution concentrations less than $1 \mathrm{~mol} / \mathrm{L}$, chromium removal efficiency reached 96\% by increasing the feed solution concentration to about $11 \mathrm{mg} / \mathrm{L}$. Mondal et al reported that in direct osmosis, by increasing the concentration of draw solution, the removal rate of heavy metals also increased. The water 
flux also increased by increasing the concentration of draw solution, thereby, preventing the passage of $\mathrm{As}(\mathrm{V})$ from the membrane to the draw solution (32). On the other hand, when the concentration of feed solution exceeded $11 \mathrm{mg} / \mathrm{L}$, changes in the draw solution had on significant effect on the removal of chromium; chromium removal also followed a downward trend. In addition, a study by Cui et al (10) reported similar results, despite a greater slope in the trend line compared to this study. At a draw solution concentration of $1 \mathrm{~mol} / \mathrm{L}$, removal of heavy metals reached $99.8 \%$ by increasing the concentration of feed solution to $1000 \mathrm{mg} / \mathrm{L}$. However, by increasing the initial concentration of feed solution to 2000 and 5000 $\mathrm{mg} / \mathrm{L}$, removal efficiency slightly decreased (99.6\%). Conversely, Han reported that the removal rate of arsenic is not directly correlated with the concentration of draw solution (33). The results of numerical optimization in the used program showed the following optimal conditions: initial chromium concentration in the feed solution, 4 $\mathrm{mg} / \mathrm{L}$; draw solution concentration $\left(\mathrm{MgCl}_{2}\right), 1.27 \mathrm{~mol} / \mathrm{L}$; and experiment time, $90 \mathrm{~min}$. Under these conditions, the removal efficiency of chromium and flux of recycled water were $85.58 \%$ and $15.6 \mathrm{LMH}$, respectively. The suitability of the model was also $78.8 \%$. In order to verify the predicted results by the model under the predicted optimal conditions, three additional experiments were performed in the laboratory, the results of which are presented in Table 4, along with the predicted results by the model. The results showed that the error rate and SD of the experimental and predicted data were low, and the model was a good fit to the experimental data.

When there are several responses in a process, the optimal conditions can be graphically presented using an overlay plot of all contour plots. Graphical optimization represents the possible responses for each factor; areas that fit the optimal criteria are shaded. By selecting the minimum criteria for chromium removal and water flux ( $90 \%$ and 15 $\mathrm{LMH}$, respectively), the optimal region is demonstrated in Figure 4. This region showed the optimal condition for chromium removal and water flux.

\section{Conclusion}

Considering the simplicity and cost-effectiveness of direct osmosis and its relatively high efficiency in water

Table 4. Verification of the predicted results under optimal conditions

\begin{tabular}{lcc}
\hline Conditions & $\begin{array}{c}\text { Water flux } \\
\text { (LMH) }\end{array}$ & $\begin{array}{c}\text { Chromium } \\
\text { removal } \\
\text { (\%) }\end{array}$ \\
\hline Feed solution concentration: $4 \mathrm{mg} / \mathrm{L}$ & & \\
Draw solution concentration: $1.27 \mathrm{~mol} / \mathrm{L}$ & & \\
Experimental time: $90 \mathrm{~min}$ & & \\
Experimental data & 17.85 & 87.5 \\
Model response & 15.65 & 85.58 \\
Error & 2.2 & 1.92 \\
SD & $0.95 \pm$ & $0.68 \pm$ \\
\hline
\end{tabular}

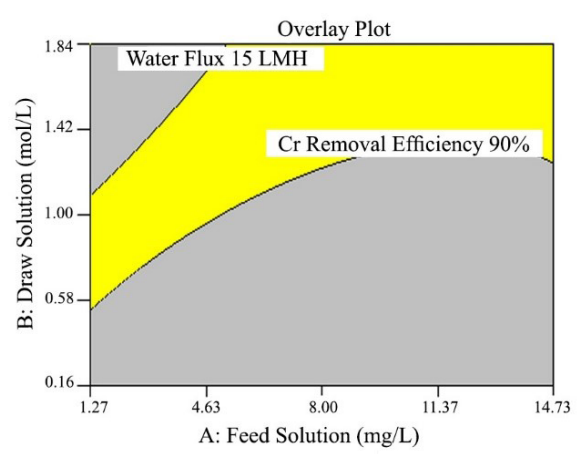

Figure 4. The overlay plot of the water flux and chromium removal.

recycling and chromium removal from electroplating wastewater, membranes can be used in the treatment of wastewater. On the other hand, RSM and CCD can be applied to optimize the effective parameters in chromium removal and water flux in the treatment of electroplating wastewater. Based on the results, the optimal conditions include a feed solution concentration of $4 \mathrm{mg} / \mathrm{L}$, draw solution concentration of $1.27 \mathrm{~mol} / \mathrm{L}$, and experiment time of 90 minutes; under these conditions, water flux and chromium removal efficiency were 15.6 LMH and $85.58 \%$, respectively. Regarding removal efficiency, the amount of chromium in the effluent of the process was within the standard limits for the effluent discharge into the environment, established by Iran's Department of Environment.

It is recommended to investigate the effect of temperature, $\mathrm{pH}$, and other types of draw solutions in future studies.

\section{Acknowledgments}

The authors would like to gratitude Research Vice Chancellor of Qazvin University of Medical Sciences for Financial support of this project (No. 14003407).

\section{Ethical issues}

The authors certify that all data collected during the study are as stated in this manuscript, and no data from the study has been or will be published separately elsewhere.

\section{Competing interests}

The authors declare that they have no competing interests.

\section{Authors' contributions}

All authors contributed equally to data collection and manuscript approval.

\section{References}

1. Fu F, Wang Q. Removal of heavy metal ions from wastewaters: a review. J Environ Manage 2011; 92(3): 40718. doi: 10.1016/j.jenvman.2010.11.011.

2. Mondal M, Dutta M, De S. A novel ultrafiltration grade nickel iron oxide doped hollow fiber mixed matrix membrane: spinning, characterization and application in heavy metal removal. Sep Purif Technol 2017; 188: 155-66. 
doi: $\quad$ 10.1016/j.seppur.2017.07.013.

3. Jaishankar $M$, Tseten $T$, Anbalagan $N$, Mathew BB, Beeregowda KN. Toxicity, mechanism and health effects of some heavy metals. Interdiscip Toxicol 2014; 7(2): 60-72. doi: 10.2478/intox-2014-0009.

4. Pratush A, Kumar A, Hu Z. Adverse effect of heavy metals (As, $\mathrm{Pb}, \mathrm{Hg}$, and $\mathrm{Cr}$ ) on health and their bioremediation strategies: a review. Int Microbiol 2018; 21(3): 97-106. doi: 10.1007/s10123-018-0012-3.

5. Ahmad N, Sereshti H, Mousazadeh M, Rashidi Nodeh H, Kamboh MA, Mohamad S. New magnetic silica-based hybrid organic-inorganic nanocomposite for the removal of lead(II) and nickel(II) ions from aqueous solutions. Mater Chem Phys 2019; 226: 73-81. doi: 10.1016/j. matchemphys.2019.01.002.

6. Hamilton EM, Young SD, Bailey EH, Watts MJ. Chromium speciation in foodstuffs: a review. Food Chem 2018; 250: 105-12. doi: 10.1016/j.foodchem.2018.01.016.

7. Patra DK, Pradhan C, Patra HK. An in situ study of growth of Lemongrass Cymbopogon flexuosus (Nees ex Steud.) W. Watson on varying concentration of Chromium $\left(\mathrm{Cr}^{+6}\right)$ on soil and its bioaccumulation: perspectives on phytoremediation potential and phytostabilisation of chromium toxicity. Chemosphere 2018; 193: 793-9. doi: 10.1016/j.chemosphere.2017.11.062.

8. Carolin CF, Kumar PS, Saravanan A, Joshiba GJ, Naushad M. Efficient techniques for the removal of toxic heavy metals from aquatic environment: a review. J Environ Chem Eng 2017; 5(3): 2782-99. doi: 10.1016/j.jece.2017.05.029.

9. Bazrafshan E, Mohammadi L, Ansari-Moghaddam A, Mahvi AH. Heavy metals removal from aqueous environments by electrocoagulation process- a systematic review. J Environ Health Sci Eng 2015; 13: 74. doi: 10.1186/ s40201-015-0233-8.

10. Cui Y, Ge Q, Liu XY, Chung TS. Novel forward osmosis process to effectively remove heavy metal ions. J Memb Sci 2014; 467: 188-94. doi: 10.1016/j.memsci.2014.05.034.

11. You S, Lu J, Tang CY, Wang X. Rejection of heavy metals in acidic wastewater by a novel thin-film inorganic forward osmosis membrane. Chem Eng J 2017; 320: 532-8. doi: 10.1016/j.cej.2017.03.064.

12. Lee CG, Lee S, Park JA, Park C, Lee SJ, Kim SB, et al. Removal of copper, nickel and chromium mixtures from metal plating wastewater by adsorption with modified carbon foam. Chemosphere 2017; 166: 203-11. doi: 10.1016/j.chemosphere.2016.09.093.

13. Teymoori M, Ghanbari R, Jamali HA. Applying the response surface method to optimize the removal of lead and cobalt from aquatic environments using electrocoagulation. Fresen Environ Bull 2018; 27(10): 6711-21.

14. Huang J, Yuan F, Zeng G, Li X, Gu Y, Shi L, et al. Influence of $\mathrm{pH}$ on heavy metal speciation and removal from wastewater using micellar-enhanced ultrafiltration. Chemosphere 2017; 173:199-206. doi: 10.1016/j.chemosphere.2016.12.137.

15. Chekli L, Phuntsho S, Kim JE, Kim J, Choi JY, Choi JS, et al. A comprehensive review of hybrid forward osmosis systems: performance, applications and future prospects. J Memb Sci 2016; 497: 430-49. doi: 10.1016/j.memsci.2015.09.041.

16. Eyvaz M, Arslan S, Imer D, Yuksel E, Koyuncu I. Forward

17. Osmosis Membranes-A Review: Part I. [cited 2019 Jan 10] Available from: https://www.intechopen.com/ books/osmotically-driven-membrane-processes-approachdevelopment-and-current-status/forward-osmosis-membranesa-review-part-i.

18. Emamjomeh MM, Jamali HA, Moradnia M. Optimization of nitrate removal efficiency and energy consumption using a batch monopolar electrocoagulation: prediction by RSM method. J Environ Eng 2017; 143(7): 04017022. doi: 10.1061/(ASCE)EE.1943-7870.0001210.

19. Dehghani MH, Faraji M, Mohammadi A, Kamani H. Optimization of fluoride adsorption onto natural and modified pumice using response surface methodology: isotherm, kinetic and thermodynamic studies. Korean J Chem Eng 2017; 34(2): 454-62. doi: 10.1007/s11814-0160274-4.

20. Khoshnamvand N, Kord Mostafapour F, Mohammadi A, Faraji M. Response surface methodology (RSM) modeling to improve removal of ciprofloxacin from aqueous solutions in photocatalytic process using copper oxide nanoparticles (CuO/UV). AMB Express 2018; 8(1): 48. doi: 10.1186/ s13568-018-0579-2.

21. Nariyan E, Sillanpaa M, Wolkersdorfer C. Uranium removal from Pyhäsalmi/Finland mine water by batch electrocoagulation and optimization with the response surface methodology. Sep Purif Technol 2018; 193: 386-97. doi: 10.1016/j.seppur.2017.10.020.

22. Karichappan T, Venkatachalam S, Jeganathan PM. Optimization of electrocoagulation process to treat grey wastewater in batch mode using response surface methodology. J Environ Health Sci Eng 2014; 12(1): 29. doi: 10.1186/2052-336x-12-29.

23. Xie W, He F, Wang B, Chung TS, Jeyaseelan K, Armugam A, et al. An aquaporin-based vesicle-embedded polymeric membrane for low energy water filtration. J Mater Chem A 2013; 1(26): 7592-600. doi: 10.1039/C3TA10731K.

24. Vital B, Bartacek J, Ortega-Bravo JC, Jeison D. Treatment of acid mine drainage by forward osmosis: heavy metal rejection and reverse flux of draw solution constituents. Chem Eng J 2018; 332: 85-91. doi: 10.1016/j.cej.2017.09.034.

25. Nasr P, Sewilam H. Forward osmosis: an alternative sustainable technology and potential applications in water industry. Clean Technol Environ Policy 2015; 17(7): 207990. doi: 10.1007/s10098-015-0927-8.

26. Jamali HA, Moradnia M. Optimizing functions of coagulants in treatment of wastewater from metalworking fluids: prediction by RSM method. Environ Health Eng Manag 2018; 5(1): 15-21. doi: 10.15171/ehem.2018.03.

27. Najib T, Solgi M, Farazmand A, Heydarian SM, Nasernejad B. Optimization of sulfate removal by sulfate reducing bacteria using response surface methodology and heavy metal removal in a sulfidogenic UASB reactor. J Environ Chem Eng 2017; 5(4): 3256-65. doi: 10.1016/j. jece.2017.06.016.

28. Mourabet M, El Rhilassi A, El Boujaady H, Bennani-Ziatni M, Taitai A. Use of response surface methodology for optimization of fluoride adsorption in an aqueous solution by Brushite. Arab J Chem 2017; 10(Suppl 2): S3292-302. doi: 10.1016/j.arabjc.2013.12.028.

29. Moradnia M, Panahifard M, Dindarlo K, Jamali HA. Optimizing potassium ferrate for textile wastewater treatment by RSM. Environ Health Eng Manag 2016; 3(3): 137-42. doi: 10.15171/ehem.2016.12. 
30. Doosti F, Ghanbari R, Jamali HA, Karyab H. Optimizing Fenton process for olive mill wastewater treatment using response surface methodology. Fresen Environ Bull 2017; 26(10): 5942-53.

31. Zhao P, Gao B, Yue Q, Liu S, Shon HK. The performance of forward osmosis in treating high-salinity wastewater containing heavy metal $\mathrm{Ni}^{2+}$. Chem Eng J 2016; 288: 56976. doi: 10.1016/j.cej.2015.12.038.

32. Liu C, Lei X, Wang L, Jia J, Liang X, Zhao X, et al. Investigation on the removal performances of heavy metal ions with the layer-by-layer assembled forward osmosis membranes. Chem Eng J 2017; 327: 60-70. doi: 10.1016/j. cej.2017.06.070,

33. Mondal P, Hermans N, Kim Tran AT, Zhang Y, Fang Y, Wang $\mathrm{X}$, et al. Effect of physico-chemical parameters on inorganic arsenic removal from aqueous solution using a forward osmosis membrane. J Environ Chem Eng 2014; 2(3): 1309-16. doi: 10.1016/j.jece.2014.04.015.

34. Han Y. A study of heavy metal rejection by forward osmosis [dissertation]. Pokfulam, Hong Kong: University of Hong Kong; 2015. doi: 10.5353/th_b5673732. 